\title{
Effect of female size on host selection by a koinobiont insect parasitoid (Hymenoptera: Braconidae: Aphidiinae)
}

\author{
Dionyssios LYKOURESSIS ${ }^{1}$, NiKOlaOs GARANTONAKIS ${ }^{1}$, DiONYSSIOS PERDIKIS ${ }^{1}$, ArgYro FANTINOU $^{2}$ \\ and ANDRONIKOS MAUROMOUSTAKOS ${ }^{3}$ \\ ${ }^{1}$ Laboratory of Agricultural Zoology and Entomology, Agricultural University of Athens, Iera Odos 75, 11855 Athens, Greece; \\ e-mail: dperdikis@aua.gr \\ ${ }^{2}$ Laboratory of Ecology and Environmental Sciences, Agricultural University of Athens, Iera Odos 75, 11855 Athens, Greece \\ ${ }^{3}$ Agricultural Statistics Laboratory, 101 AGRX, University of Arkansas, Fayetteville, AR 72701, USA
}

Key words. Hymenoptera, Braconidae, Aphidius colemani, Hemiptera, Aphis gossypii, Myzus persicae, aphid, body size, host selection

\begin{abstract}
Body size is a main fitness component of insect parasitoids. We assessed the potential influence of maternal size of the parasitoid wasp Aphidius colemani Viereck (Hymenoptera: Braconidae: Aphidiinae) on its ability to parasitize the different instars of Aphis gossypii Glover (Hemiptera: Aphididae) on eggplant and cucumber. In the experiments "small" vs "large" parasitoid females were used. Females oviposited in all instars but more of the smaller hosts were parasitized. Host selection was affected by female size and the larger hosts were more frequently mummified by the large than the small females. Thus, parasitoid female size influenced host selection. This could affect the potential of the parasitoid to exploit populations of aphids that differ in their size structure. The importance of these results in terms of the ecological adaptations of the parasitoid and their implication for biological control are discussed.
\end{abstract}

\section{INTRODUCTION}

Changes in the behaviour of optimal foragers results in an increase in profitable gain when exploiting resources of variable quality. These adaptations are difficult to investigate as resource quality and quantity may vary in space and time. Nevertheless, specific classes of organisms such as parasitoids are ideal organisms for testing hypotheses regarding the fitness consequences of reproductive behaviour. The key feature is that their development is entirely dependent on the resources provided by a single host. Based on their development and host usage strategies parasitoids have been divided into two groups: koinobionts and idiobionts (Askew \& Shaw, 1986). Koinobiont parasitoids allow further development of the host after parasitism, whereas idiobionts parasitize nongrowing hosts (eggs or pupae) and /or arrest the development of hosts by paralysis or killing it during oviposition.

Foraging theory predicts that optimal host selection aims to maximize the profits for the next parasitoid generation (Hubbard \& Cook, 1978; Pyke, 1984). Taking into account that the host represents a finite food resource, acceptable host individuals should satisfy the minimum resource threshold for the parasitoid larva's growth (Vet et al., 1994; Harvey et el., 1995; Mackauer et al., 1996). In fact, the finite resources available during parasitoid development result in a close association between host size and offspring size (Harvey, 2005). Therefore, fitness of the offspring is largely dependent on the mother's ability to accurately assess the suitability of the host (Mousseau \& Dingle, 1991). Accepted host individuals apparently satisfy a minimum quality threshold for the parasitoid larva's growth and development but presumably should cover its nutritional needs at a different success rate (Mackauer et al., 1996). However, apart from host traits, host selection is also based on behavioural and physiological properties of the foraging female, such as her physiological state, age (Völkl \& Mackauer, 1990; Weisser, 1994; Mackauer et al., 1996), previous experience (Grasswitz, 1998) and search time allocation (Kouamé \& Mackauer, 1991).

Host choice decisions among hosts of dissimilar size may be affected by the size of the foraging female. Parasitoid female size is related to reproductive potential as well as to foraging efficiency (Godfray, 1994; Visser, 1994; Jervis \& Copland, 1996; Ellers et al., 2001; Ellers \& Jervis, 2003; Jervis et al., 2008). In particular, large females of Aphidius colemani Viereck (Hymenoptera: Braconidae: Aphidiinae) encounter hosts faster than small females (Ode et al., 2005). Host selection is also affected by host defensive capability, which might increase the parasitoid's risk during host manipulation and reduce the time available for searching. Thus, it may be advantageous for females to be large as they are more successful at parasitizing large hosts. Evidence for this is derived from studies on mortality risk (Mackauer et al., 1996) and handling time (Shirota et al., 1983; Chau \& Mackauer, 2000) during host manipulation and search time allocation (Kouamé \& Mackauer, 1991), which reveal positive correlations with host size. Despite this association between maternal size and host selection this topic has received a little attention. 
Rotheray et al. (1984) and Henry et al. (2006) show there is a positive association between female parasitoid size and host size. In both these studies, small and large females were produced by rearing the parasitoid in a small or a large host.

Therefore, it remains unclear whether an effect of female size on host selection occurs in sympatric females. In fact, such an approach would examine to what extent intra-population female size variation could alter the frequencies of different hosts attacked.

Searching for hosts occurs on plants and thus plant traits might affect host searching and handling. For example, characteristics of plants such as trichomes can interfere with the foraging effectiveness of parasitoids (Inbar \& Gerling, 2008). We hypothesize that large parasitoid females could be more efficient than small ones in overcoming the difficulties posed by the structure of plant substrates.

The aim of the work reported here was to determine if host selection by a koinobiont aphid parasitoid is affected by female size. Our objectives were evaluated by studying the host selection of "small" vs. "large" female parasitoids obtained from the same population. As hosts all the nymphal instars of the aphid host species were provided. The effects were assessed on two species of plant in order to determine whether plants affect host selection by parasitoids. In each experiment, the parasitoid females were provided with host instars in equal ratios.

\section{MATERIAL AND METHODS}

\section{Experimental material}

Aphidius colemani is a koinobiont solitary oligophagous aphid parasitoid (Starý, 1975; Messing \& Rabasse, 1995). Myzus persicae (Sulzer), and particularly Aphis gossypii Glover (Hemiptera: Aphididae), are suitable hosts for the development and reproduction of this parasitoid (van Steenis, 1993; Sampaio et al., 2008), and it prefers to oviposit in the first- and secondinstar nymphs (Perdikis et al., 2004). Although A. colemani is widely used in the biological control of A. gossypii and M. persicae infesting greenhouse crops (van Lenteren, 2003; Yano, 2006), the factors that influence its host selection are poorly studied (Grasswitz, 1998).

M. persicae were reared on pepper plants (Capsicum annum L.) (cv. Vidi) and A. gossypii on eggplants (Solanum melongena L.) (cv. Bonica). Both aphid cultures were initiated with aphids collected on the respective host plants on the campus of the Agricultural University of Athens. Aphid cultures were maintained in a glasshouse in wooden framed cages $(80 \times 80 \times$ $70 \mathrm{~cm})$ at an average temperature of $22.5 \pm 2.5^{\circ} \mathrm{C}($ mean \pm SD) under natural lighting.

Aphidius colemani adults, initially obtained from mummies of A. gossypii collected on Hibiscus syriacus L. (family Malvaceae) in Athens, were reared continuously on the aphid M. persicae on potted pepper plants (cv. Vidi) for about 3 years. Potted pepper plants infested with $M$. persicae were each covered with a plastic cage. Each cage $(11 \mathrm{~cm}$ in diameter and 30 $\mathrm{cm}$ high) was made of a sheet of PVC ( $0.4 \mathrm{~mm}$ thick) and had two openings $(9 \times 9 \mathrm{~cm})$, which along with the top opening of the cage were covered with fine muslin for ventilation. In each cage, 15-20 newly emerged parasitoids were released and provided with food in the form of droplets of dilute honey placed on the muslin at the top of the cage. The cages were placed in a growth cabinet at $25 \pm 0.5^{\circ} \mathrm{C}, 65 \pm 5 \% \mathrm{RH}$, and $16 \mathrm{~L}: 8 \mathrm{D}$ photoperiod. Two days after emergence, the parasitoids were transferred with the aid of an insect aspirator to another cage containing a pepper plant infested with aphids.

The parasitoids used in the experiments were obtained by placing pepper plant leaves bearing mummies of M. persicae in plastic cages $(20 \mathrm{~cm}$ in diameter and $30 \mathrm{~cm}$ in height). Each cage had a round opening in its side covered with muslin as was the the top opening. These cages were kept in a growth cabinet at $25 \pm 0.5^{\circ} \mathrm{C}, 65 \pm 5 \% \mathrm{RH}$, and $16 \mathrm{~L}: 8 \mathrm{D}$ photoperiod. Eight hours after the first parasitoid emerged, 20-30 were transferred to similar cages, where they were kept for $24 \mathrm{~h}$ for mating. The females were then carefully collected by means of an insect aspirator for use in the experiments. These females were similarly supplied with droplets of dilute honey. Thus, the parasitoids did not have any previous contact with the aphids.

\section{Experimental procedure}

Female parasitoid size and host selection

The effect of female parasitoid size on host selection was determined by using randomly selected small or large females, the length of which was evaluated by eye. Body measurements were not taken in advance because it could affect their subsequent behaviour. Each female was left to forage in an arena where all instars of $A$. gossypii were present. At the end of the experiments, the parasitoids' right hind tibial length was measured under a stereomicroscope equipped with an ocular micrometer.

The experiments were conducted in plastic Petri dishes $(9 \mathrm{~cm}$ in diameter and $1.5 \mathrm{~cm}$ in height) with a mesh-covered hole (3 $\mathrm{cm}$ diameter) in their lids to reduce the build up of humidity. A leaf of eggplant (cv. Bonica) or cucumber (cv. Brunex) was placed abaxial surface uppermost on a layer of cotton wool moistened with water resting on the bottom of each dish. Ten individuals of each instar of $A$. gossypii (i.e., 40 aphids in total) were placed on the eggplant or cucumber leaf, using a fine paintbrush and left for $1 \mathrm{~h}$ to settle. Then, a female parasitoid, obtained as described above, was released in the dish. After the attack of the first aphid, the dish was transferred to a growth cabinet at $25 \pm 0.5^{\circ} \mathrm{C}, 65 \pm 5 \%$ R.H, and $16 \mathrm{~L}: 8 \mathrm{D}$ photoperiod, and the parasitoid allowed to forage for $1 \mathrm{~h}$. Then, it was removed and the aphids of each instar were placed in separate dishes on an eggplant or a cucumber leaf, respectively. The sizes of the small and large female-maternal parasitoids are shown in Table 1. The leaf in each dish was replaced with a new one every other day, and the aphids were transferred onto the new leaf. The dishes were inspected every day. The number of mummies that developed in the dishes with each host instar was recorded.

\section{Data analysis}

The length of the hind tibia was compared among the females of the different categories (small and large in size and randomly selected) using one-way ANOVA.

Numbers of mummies that developed were analyzed using a Generalized Linear Model (GLM) with Poisson errors, with host plant, size-class of the parasitoid females (small or large) and the host instar as factors.

In the above analyses, data were transformed employing a Box-Cox transformation. In all cases, means were separated using contrasts $(\mathrm{P}=0.05)$.

Analyses were done using statistical package JMP 7.0.1 (SAS Institute Inc., 2007). 
TABLE 1. Length ( $\mathrm{mm} \pm \mathrm{SE}$ ) of the hind tibiae of the "small" and "large" females used to parasitize the aphids on eggplant and cucumber.

\begin{tabular}{|c|c|c|}
\hline Parasitoid size class & \multicolumn{2}{|c|}{ Host plant } \\
\hline Female size & Eggplant & Cucumber \\
\hline Small & $\begin{array}{c}0.33 \pm 0.009 a \\
(23)\end{array}$ & $\begin{array}{c}0.35 \pm 0.01 \mathrm{a} \\
(25)\end{array}$ \\
\hline Large & $\begin{array}{c}0.54 \pm 0.01 b \\
(18)\end{array}$ & $\begin{array}{c}0.55 \pm 0.01 \mathrm{~b} \\
(19)\end{array}$ \\
\hline
\end{tabular}

Values bearing the same lower case letters were not significantly different between female size classes and between same sized females on different host plants. Numbers in parentheses indicate the number of replicates (parasitoid females) used in each case.

\section{RESULTS}

\section{Size of the maternal parasitoids}

The length of the hind tibiae of the "small" and "large" females used in the experiments is shown in Table 1. The average length of 100 females randomly selected from the cultures was $0.40 \pm 0.01 \mathrm{~mm}$. The large and small females differed significantly in terms of their hind-tibial length $(\mathrm{F}=19.99$, df $=4,181, \mathrm{P}<0.01)$, however, the within size class variation of the small and large females used in eggplant and cucumber experiments did not differ significantly $(\mathrm{F}=1.57, \mathrm{df}=1,46, \mathrm{P}>0.22$ and $\mathrm{F}=0.2, \mathrm{df}$ $=1,35, \mathrm{P}>0.79$, for the small and the large females, respectively) (Table 1 ).

\section{Host selection and female size}

The total number of nymphs on eggplant and cucumber that developed into mummies after exposure to small and large females, respectively, is shown in Fig. 1. The number of $A$. gossypii nymphs mummified by the large parasitoids was significantly higher than that by the small parasitoids on both eggplant and cucumber $\left(\chi^{2}=17.81, \mathrm{df}\right.$

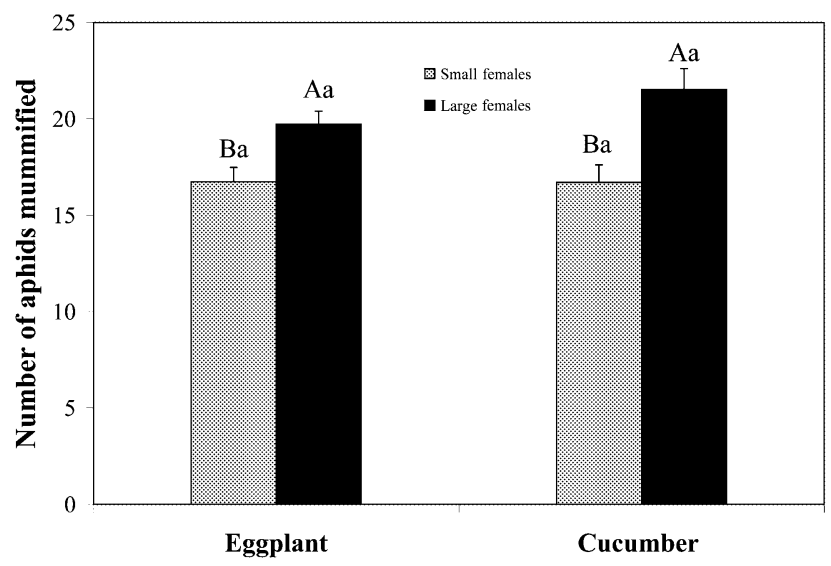

Fig. 1. Total number (mean \pm S.E.) of mummified nymphs of Aphis gossypii that developed on eggplant and cucumber after parasitization by "small" and "large" females of the parasitoid Aphidius colemani at $25^{\circ} \mathrm{C}$. Columns with the same lower case letters were not significantly different between plants and those with the same upper case letters were not significantly different between different female size classes on a given host plant.
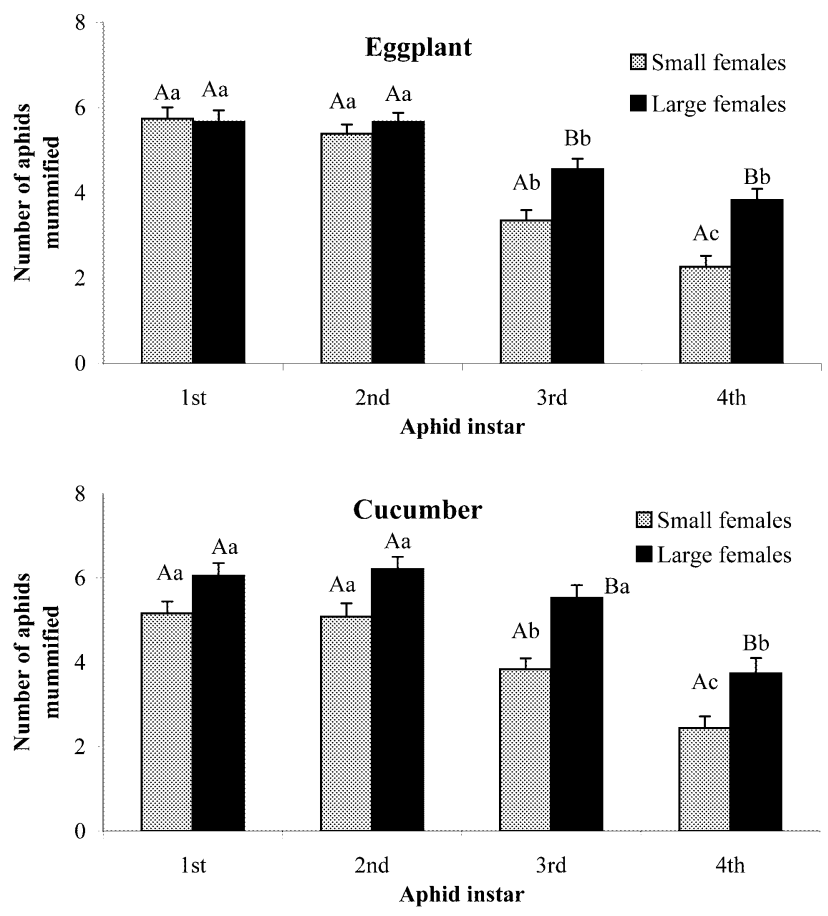

Fig. 2. Number (mean \pm S.E.) of mummified nymphs of all instars of Aphis gossypii that developed on eggplant and cucumber after parasitization by "small" and "large" females of the parasitoid Aphidius colemani at $25^{\circ} \mathrm{C}$. Columns with the same lower case letters were not significantly different among instars and those with the same upper case letters were not significantly different between different size classes for a given instar.

$=1,81, \mathrm{P}<0.01)$. However, it should be noted, that the contrast between the number of nymphs parasitized by the large vs small parasitoids was stronger on cucumber than on eggplant $\left(\chi^{2}=15.15\right.$, df $=1, \mathrm{P}<0.001$ and $\chi^{2}=$ $5.22, \mathrm{df}=1, \mathrm{P}<0.023$, on each host plant, respectively).

The effect of the host plant and the interaction between female size and host plant were not significant $\left(\chi^{2}=0.55\right.$, $\mathrm{df}=1,81, \mathrm{P}>0.45 ; \chi^{2}=1.03, \mathrm{df}=1,81, \mathrm{P}>0.30$, respectively). For each female size class the number of mummified nymphs was similar on the two host plants.

Female size and host instar had a significant effect on the number of aphids mummified on both plants $\left(\chi^{2}=\right.$ 91.07, df $=3,328, \mathrm{P}<0.001 ; \chi^{2}=22.45$, df $=1,328, \mathrm{P}<$ $0.001)$ and the interaction was also significant $\left(\chi^{2}=8.01\right.$, $\mathrm{df}=3,328, \mathrm{P}<0.043)$.

Generally, more mummies were recorded after exposing $1^{\text {st }}$ and $2^{\text {nd }}$ instars, than $3^{\text {rd }}$ and particularly $4^{\text {th }}$ instars aphids to parasitization (Fig. 2). The number of mummies developing in $1^{\text {st }}$ and $2^{\text {nd }}$ instar aphids was similar when parasitized by small and large parasitoids on both eggplant and cucumber. However, parasitization by large parasitoids resulted in a significantly higher number of mummies developing in $3^{\text {rd }}$ and $4^{\text {th }}$ instar $A$. gossypii than when parasitized by small parasitoids on both host plants (Fig. 2).

For small parasitoids, the number of mummies produced significantly decreased with increase in host instar on both eggplant and cucumber. However, for large para- 
sitoids there was no host plant effect. On eggplant, the numbers of mummies developing in $3^{\text {rd }}$ and the $4^{\text {th }}$ instar aphids were similar, whereas on cucumber although similar for $1^{\text {st }}, 2^{\text {nd }}$ and $3^{\text {rd }}$ instar aphids it was significantly less in $4^{\text {th }}$ instar aphids.

\section{DISCUSSION}

Our results indicate the large females are capable of producing a higher total number of mummies than small females (Fig. 1). Thus, within a population of parasitoids the larger ones are likely to contribute more to the increase of the parasitoid population or suppression of the host population. It is likely that this increased host attack rate can be attributed to the greater energy reserves and more advanced egg production of the larger females (Ellers et al., 1998; Bezemer et al., 2005).

The results indicate that $1^{\text {st }}$ and $2^{\text {nd }}$ instar aphids were more likely to be parasitized, regardless of the size of the parasitoid. The high potential of $A$. colemani to reduce the numbers of the smaller hosts is likely to positively affect its effectiveness. This is because aphids parasitized early in their life are unlikely to produce offspring (van Steenis \& El-Khawass, 1995) and young aphids are more abundant in the early stages of aphid population increase (Lykouressis, 1982; Lykouressis \& van Emden, 1983; Kouamé \& Mackauer, 1991).

However, large females appeared more effective than the small females in parasitizing the larger hosts, when measured in terms of the number of mummies produced (Fig. 1). Therefore our results support those of Rotheray et al. (1984) and Henry et al. (2006) who report a positive relationship between female size and that of the hosts mummified. However, these studies did not measure intra-population variation as the parasitoids were reared from different host species and differed greatly in size. Our study shows that intra-population variation in female size can affect whether the larger sized hosts are parasitized.

Evidence was also gathered on the importance of the female size in the exploitation of patches of hosts in different environments. Small females searching on cucumber caused the mummification of relatively fewer aphids than large females, in comparison to eggplant, although there were no differences in the sizes of the females in each size category that were used to parasitize the aphids on the two host plants (Table 1). The reason for this may be that cucumber leaves bear a more dense covering of trichomes, which makes it more difficult for the parasitoid to handle the larger aphids. Therefore, the larger females may also significantly increase the flexibility of the parasitoid population when exploiting complex environments.

These results might indicate possible ways of manipulating a host plant-aphid-parasitoid system for improving the effectiveness of biological control. Studies on host selection indicate that the production of less hairy cucumber cultivars could enhance the effectiveness of Encarsia formosa Gahan (Hymenoptera: Aphelinidae) (van Lenteren et al., 1995) or the use of a larger host to increase the female offspring ratio in the mass rearing of the parasitoid Diglyphus isaea (Walker) (Hymenoptera: Eulophidae) (Ode \& Heinz, 2002).

In conclusion, this study indicates that plasticity in female size can increase a parasitoid's effectiveness when exploiting a host consisting of different sized individuals.

ACKNOWLEDGEMENTS. Many thanks are due to Y. Symillides and A. Katsileros of the Agricultural University of Athens for their assistance with the statistical analyses.

\section{REFERENCES}

AsKew R.R. \& Shaw M.R. 1986: Parasitoid communities: Their size, structure and development. In Waage J. \& Greathead D. (eds): Insect Parasitoids. Academic Press, London, pp. 225-264.

Bezemer T.M., Harvey J.A. \& Mills N.J. 2005: Influence of adult nutrition on the relationship between body size and reproductive parameters in a parasitoid wasp. Ecol. Entomol. 30: $571-580$.

Chau A. \& Mackauer M. 2000: Host-instar selection in the aphid parasitoid Monoctonus paulensis (Hymenoptera: Braconidae, Aphidiinae): a preference for small pea aphids. Eur. J. Entomol. 97: 347-353.

Ellers J. \& Jervis M. 2003: Body size and the timing of egg production in parasitoid wasps. Oikos 102: 164-172.

Ellers J., van Alphen J.J.M. \& Sevenster J.G. 1998: A field study of size-fitness relationships in the parasitoid Asobara tabida. J. Anim. Ecol. 67: 318-324.

Ellers J., MinKa B. \& van Alphen J.J.M. 2001: Seasonal changes in female size and its relation to reproduction in the parasitoid Asobara tabida. Oikos 92: 309-314.

Godfray H.C.J. 1994: Parasitoids: Behavioral and Evolutionary Ecology. Princeton University Press, Princeton, NJ, $473 \mathrm{pp}$.

GRASSWITZ T.R. 1998: Effect of adult experience on the hostlocation behavior of the aphid parasitoid Aphidius colemani Viereck (Hymenoptera: Aphidiidae). Biol. Control 12: $177-181$.

Harvey J.A. 2005. Factors affecting the evolution of development strategies in parasitoids wasps: the importance of functional constraints and incorporating complexity. Entomol. Exp. Appl. 117: 1-13.

Harvey J.A., Harvey I.F. \& Thompson D.J. 1995: The effect of host nutrition on growth and development of the parasitoid wasp Venturia canescens. Entomol. Exp. Appl. 75: 213-220.

Henry L.M., Roitberg B.D. \& Gillespie D.R. 2006: Covariance of phenotypically plastic traits induces an adaptive shift in host selection behaviour. Proc. R. Soc. (B) 273: 2893-2899.

HubBard S.F. \& CoOK R.M. 1978: Optimal foraging by parasitoid wasps. J. Anim. Ecol. 47: 593-604.

INBAR M. \& GerLING D. 2008: Plant-mediated interactions between whiteflies, herbivores, and natural enemies. Annu. Rev. Entomol. 53: 431-448.

Jervis M.A. \& Copland M.J.W. 1996: The life cycle. In Jervis M. \& Kidd N. (eds): Insect Natural Enemies. Practical Approaches to Their Study and Evolution. Chapman \& Hall, London, pp. 63-161.

Jervis M.A., Ellers J. \& Harvey J.A. 2008: Resource acquisition, allocation and utilization in parasitoid reproductive strategies. Annu. Rev. Entomol. 53: 361-385.

KouAMÉ K.I. \& MACKAUER M. 1991: Influence of aphid size, age and behaviour on host choice by the parasitoid wasp Ephedrus californicus: a test of host-size models. Oecologia $\mathbf{8 8}$ : 197-203. 
VAN Lenteren J.C. 2003: Commercial availability of biological control agents. In van Lenteren J.C. (ed.): Quality Control and Production of Biological Control Agents. Theory and Testing Procedures. CABI, Wallingford, pp. 167-179.

van Lenteren J.C., Hua L.Z., Kamerman J.W. \& Xu R.M. 1995: The parasite-host relationship between Encarsia formosa (Hym., Aphelinidae) and Trialeurodes vaporariorum (Hom., Aleyrodidae) 26. Leaf hairs reduce the capacity of Encarsia to control greenhouse whitefly on cucumber. J. Appl. Entomol. 119: $553-559$.

LyKouressis D.P. 1982: Studies Under Controlled Conditions on the Effects of Parasites on the Population Dynamics of Sitobion Avenae (F.). Ph.D. Thesis, University of Reading, 342 pp.

LyKOURESSIS D.P. \& VAN EMDEN H.F. 1983: Factors affecting the potential increase rate ( $\left.\mathrm{e}^{\lambda}, \mathrm{PIR}\right)$, as defined by Hughes, in populations of Sitobion avenae (F.) (Hemiptera: Aphididae). Entomol. Hell. 1: 53-57.

Mackauer M., Michaud J.P. \& VolkL W. 1996: Host choice by aphidiid parasitoids (Hymenoptera: Aphidiidae): host recognition, host quality and host value. Can. Entomol. 128: 959-980.

Messing R.H. \& RABASSE J.M. 1995: Oviposition behaviour of the polyphagous aphid parasitoid Aphidius colemani Viereck (Hymenoptera: Aphidiidae). Agric. Ecosyst. Environ. 52: 13-17.

Mousseau T.A. \& Dingle H. 1991: Maternal effects in insect life histories. Annu. Rev. Entomol. 36: 511-534.

Ode P.J. \& Heinz K.M. 2002: Host-size-dependent sex ratio theory and improving mass-reared parasitoid sex ratios. Biol. Control 24: 31-41.

Ode P.J., Hopper K.R. \& Coll M. 2005: Oviposition vs. offspring fitness in Aphidius colemani parasitizing different aphid species. Entomol. Exp. Appl. 115: 303-310.

Perdikis D.C., Lykouressis D.P., Garantonakis N.G. \& Iatrou S.A. 2004: Instar preference and parasitization of Aphis gossypii and Myzus persicae (Hemiptera: Aphididae) by the parasitoid Aphidius colemani (Hymenoptera: Aphidiidae). Eur. J. Entomol. 101: 333-336.

PYKE G.H. 1984: Optimal foraging theory: a critical review. Annu. Rev. Ecol. Syst. 15: 523-575.
Rotheray G.E., Barbosa P. \& Martinat P. 1984: Host influences on life-history traits and oviposition behavior of Brachymeria intermedia (Nees) (Hymenoptera, Chalcididae). Environ. Entomol. 13: 243-247.

Sampaio M.V., Bueno V.H.P. \& Conti B.F.D. 2008: The effect of the quality and size of host aphid species on the biological characteristics of Aphidius colemani (Hymenoptera: Braconidae: Aphidiinae). Eur. J. Entomol. 105: 489-494.

SAS INSTITUTE INC. 2007: JMP, version 7.0.1.

VAN STEENIS M.J. 1993: Suitability of Aphis gossypii Glov., Macrosiphum euphorbiae (Thom.) and Myzus persicae Sulz. (Hom: Aphididae) as host for several aphid parasitoid species (Hym: Braconidae). IOBC/WPRS Bull. 16: 157-160.

van Steenis M.J. \& El-Khawass K.A.M.H. 1995: Behaviour of Aphidius colemani searching for Aphis gossypii: functional response and reaction to previously searched aphid colonies. Biocontr. Sci. Techn. 5: 339-347.

Shirota Y., Carter N., Rabbinge R. \& Ankersmit G.W. 1983: Biology of Aphidius rhopalosiphi, a parasitoid of cereal aphids. Entomol. Exp. Appl. 34: 27-34.

STARÝ P. 1975: Aphidius colemani Viereck: its taxonomy, distribution and host range (Hymenoptera, Aphidiidae). Acta Entomol. Bohemoslov. 72: 156-163.

VISSER M. 1994: The importance of being large: the relationship between size and fitness in females of the parasitoid Aphaereta minuta (Hymenoptera: Braconidae). J. Anim. Ecol. 63: 963-978.

Vet L.E.M., Datema A., Janssen A. \& Snellen H. 1994: Clutch size in a larval pupal endoparasitoid - consequences for fitness. J. Anim. Ecol. 63: 807-815.

VölKL W. \& Mackauer M. 1990: Age-specific pattern of host discrimination by the aphid parasitoid Ephedrus californicus Baker (Hym.: Aphidiidae). Can. Entomol. 122: 349-361.

Weisser W.W. 1994: Age-dependent foraging behaviour and host instar preference of the aphid parasitoid Lysiphlebus cardui. Entomol. Exp. Appl. 70: 1-10.

YANO E. 2006: Ecological considerations for biological control of aphids in protected culture. Popul. Ecol. 48: 333-339.

Received August 1, 2008; revised and accepted March 3, 2009 